\title{
Suspension feeder diversity enhances community filtration rates in different flow environments
}

\author{
Matthew A. Whalen*, John J. Stachowicz \\ Department of Evolution \& Ecology, University of California, Davis, CA 94923, USA
}

\begin{abstract}
The functioning of ecosystems results from the interplay between living organisms and their surroundings. Therefore, our ability to predict ecosystem functioning depends on our understanding of interactions between dynamic biotic and abiotic variables. Biodiversity can be influenced by the changes in the environment and can also influence ecosystem functioning, but our understanding of how environmental changes influence biodiversity-ecosystem functioning relationships remains limited. In coastal marine systems, water flow is a crucial determinant of resource delivery for sessile suspension-feeding animals and can potentially influence secondary production and the rate at which suspended materials are removed from water, determining water clarity, light penetration, and other key abiotic variables. We experimentally investigated how the presence and absence of water flow influenced phytoplankton consumption by suspension-feeder communities of varying species richness and composition. Consumer species richness enhanced filtration to the same degree in both flow conditions, despite generally decreased filtration in flow and considerable variation in the response to flow by consumers in monoculture. Species pairs filtered more than expected from monoculture performance, and species traits helped explain variance in these trends. However, there was no evidence of prey size selectivity by any consumer species, ruling this out as a mechanism underlying diversity effects. Our finding that the shape of the relationship between biodiversity and water filtration was identical in both flow conditions suggests that complementarity in this system is robust to at least one type of environmental variation.
\end{abstract}

KEY WORDS: Biodiversity-ecosystem functioning • Water filtration - Fouling community - Suspension feeding $\cdot$ Filter feeding $\cdot$ Size selectivity

*Corresponding author: mawhal@gmail.com

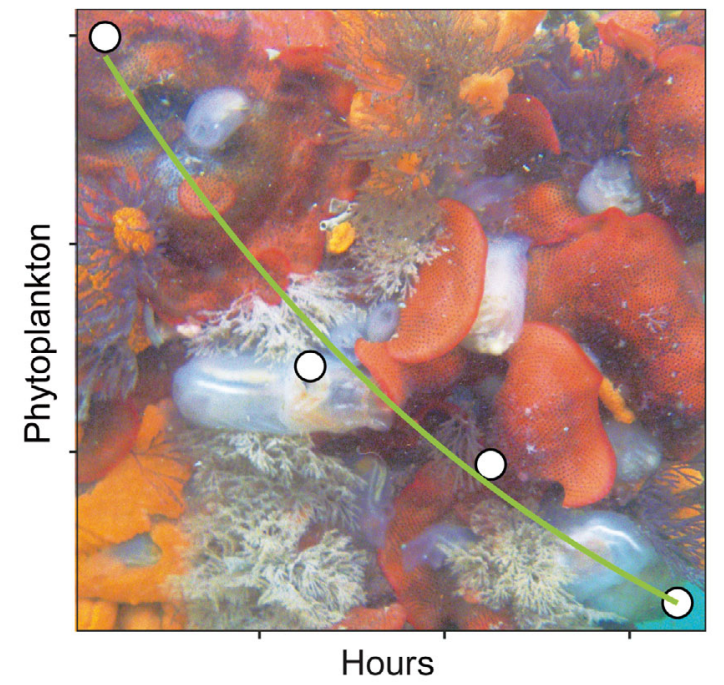

Phytoplankton consumption by sessile invertebrates is affected by diversity in morphology and feeding mechanisms.

Photo: Matthew A. Whalen

\section{INTRODUCTION}

A pressing goal of ecology is to predict how ecosystem functioning responds to biodiversity change. Species diversity is widely considered to influence ecosystem functioning, but experiments designed to test this relationship receive criticism for inadequately capturing relevant forms and scales of environmental variation that might influence the magnitude and direction of diversity effects (Cardinale et al. 2011). Accumulating evidence suggests that biodiversity becomes a better predictor of functioning over greater time scales and with higher spatial heterogeneity, because then a greater diversity of spe-

() The authors 2017. Open Access under Creative Commons by Attribution Licence. Use, distribution and reproduction are unrestricted. Authors and original publication must be credited. 
cies' traits (e.g. physiological tolerance or nutrient requirements) are required to maintain functioning across different conditions (Norberg et al. 2001, Stachowicz et al. 2008, Cardinale 2011, Reich et al. 2012, Whalen et al. 2016). Changes in both environment and biodiversity simultaneously alter ecosystem functioning (e.g. Cardinale \& Palmer 2002, Boyer et al. 2009, Eklöf et al. 2012). So, while it is clear that diversity 'matters', its importance relative to that of other ecological drivers may vary with environmental context.

Changes in environmental conditions potentially influence ecosystem functioning even if community composition remains constant at the scale of environmental change. This depends on how species respond to environmental changes and the effect of that species on a particular function (Suding et al. 2008). Functioning may respond proportionally to a change in environment if it affects all community members similarly. More likely, however, species will respond differently to environmental changes, shifting the identity of species that dominate ecosystem functioning and changing the outcomes of species interactions (Yachi \& Loreau 1999, Bruno et al. 2003, He et al. 2013). Thus, environmental variation can affect the extent to which complementarity and sampling effects occur as well as the identity of species responsible for sampling effects, potentially resulting in complementarity across contexts (Boyer et al. 2009, O'Connor et al. 2015). Thus, a fuller understanding of the roles of biodiversity depends not just on understanding the effect of diversity within a particular scenario but also on how diversity effects change across environmental scenarios.

In communities of suspension-feeding invertebrates, water flow can impact individual filterfeeding performance and community structure. Species composition often changes dramatically over small scales in places where water flow rates change quickly over space, due to changing physical stress and resource flux brought by currents and waves (e.g. Patterson \& Sebens 1989, Williams \& Carpenter 1998, Leichter \& Witman 1997). In many environments, water flow is temporally variable due to both regular (tides) and irregular (winds, storms) phenomena. This spatial and temporal variation in flow can influence species coexistence through the modification of propagule supply in metacommunities (Palardy \& Witman 2014) but also through adult responses to environmental conditions. Flow affects the feeding abilities of suspension feeders in ways that are dependent on the feeding mechanisms and morphologies of these consumers, as well as interactions between competitors (Holmes 1973, Oka- mura 1984, 1985, Sebens \& Johnson 1991, Sumerel \& Finelli 2014). While considerable work emphasizes the effects of this variation in flow on community composition, much less considers how changing flow regimes could alter the functioning of these ecosystems from the standpoint of community-wide filtration.

Given the wide variation in feeding traits among sessile suspension feeders (Riisgård \& Larsen 2010), it is plausible that diverse communities with a collection of these traits will sustain filtration across a range of flow conditions through complementarity in feeding efficiencies. Communities in these systems change over time for a variety of reasons, including disturbance (Petraitis \& Latham 1999), reproductive phenology (Edwards \& Stachowicz 2010), and interactions in the adult community (e.g. Buss 1979, Stachowicz et al. 1999, Stachowicz \& Byrnes 2006). At a given time, however, many species are potentially able co-occur at relatively small spatial scales.

Previous studies assessing how water filtration changes with consumer diversity have emphasized the importance of diet complementarity, facilitation among consumers, disturbance, and temporal scale (Cardinale \& Palmer 2002, Byrnes \& Stachowicz 2009). Following from these studies, we hypothesize that communities with mixtures of feeding and morphological traits would have higher rates of filtration. However, previous studies did not consider variation in background water flow (but see Cardinale 2011). Water flow variation is inherent to marine systems and is a critical determinant of food delivery and particle capture abilities of suspension feeders (LaBarbera 1984). Therefore, we also reasoned that the importance of diversity and trait complementarity would vary as water flow conditions altered species interactions. Investigating this widespread source of environmental heterogeneity is a natural next step in testing theories about relationships between biodiversity and ecosystem functioning (Gamfeldt et al. 2015), and we focus on how water flow affects this general relationship rather than specific species interactions.

We tested how the presence and absence of water flow influences rates of community water filtration in a sessile invertebrate community composed of a diversity of bryozoans and tunicates. We combined species in a replacement design so that the total areal cover of every community was equal. Species were selected based on availability in the field and variation in feeding mode. We measured the rate at which communities cleared phytoplankton from the water column in laboratory-based experiments. 


\section{MATERIALS AND METHODS}

\section{Consumer treatments}

We allowed experimental animals to settle and grow naturally in the field on square PVC tiles $\left(6.45 \mathrm{~cm}^{2}\right)$ attached to larger square plates $\left(103.2 \mathrm{~cm}^{2}\right)$ using industrial strength adhesive tape with hook and loop fasteners $\left(\mathrm{VELCRO}^{\circledR}\right)$. Arrays of plates were deployed at Spud Point Marina in Bodega Harbor, CA, USA $\left(38.331^{\circ} \mathrm{N},-123.058^{\circ} \mathrm{W}\right)$. As natural communities assembled, we selectively weeded tiles to isolate single individuals or colonies of the common species, 1 per tile. We then used these tiles to assemble experimental communities, standardizing each assemblage by the amount of occupied space (i.e. number of tiles). For species with erect morphologies, we selected individuals that were of similar size and that covered approximately the entire area of the tile when viewed from above. We created communities ranging from 1 to 6 species by collecting and rearranging tiles. We collected tiles from arrays over the course of $2 \mathrm{yr}(2014$ and 2015) and regularly installed new arrays of tiles over the course of experiments and for 1 yr leading up to the experiments. We used a total of 10 species of suspension feeding invertebrate in our experiments (Table 1), and we chose species based on their availability in the field, which is known to vary seasonally at this site (Edwards \& Stachowicz 2010). We used these species to create communities with $1,2,4$, and 6 species. Including monocultures, we analyzed 32 unique consumer communities, which, due to field availability, had unequal replication across trials and years.

\section{Cultured phytoplankton diets}

In each experimental trial, we provided consumers a mixture of 7 phytoplankton species independently cultured on $12 \mathrm{~h}$ light:12 $\mathrm{h}$ dark cycles using $\mathrm{F} / 2$ nutrient media. Initial cultures and all nutrient media were sourced from the National Center for Marine Algae (Boothbay, Maine, USA) and the University of Texas at Austin Culture Collection of Algae (Austin, Texas, USA). Species ranged in cell size from a few $\mu \mathrm{m}$ to over $80 \mu \mathrm{m}$ in diameter and included the following taxa: Nannochloropsis, Isochrysis, Dunalliella, Rhodomonas, Thalassiosira, Asterionellopsis, and Coscinodiscus (see Table S1 in the Supplement at www.int-res. com/articles/suppl/m570p001_supp.pdf). Although these species did not necessarily occur naturally at our field site, they span the range of the dominant phytoplankton taxa in this region. We did not use naturally occurring assemblages because of the need to conduct many trials at different times and because seasonal changes in the phytoplankton community could have made these experiments less comparable. Species were mixed in proportions to achieve similar in vivo fluorescence (Turner Instruments, San Jose, CA, USA), our proxy for phytoplankton biomass, that we were able to measure quickly and repeatedly before, during, and after experiments. We note that we were not always able to achieve the same fluorescence for all species in every trial because of limited quantities of some cultures, but all replicates within a given trial received the same quantity and composition of phytoplankton.

Table 1. Species used in filtration experiments, their phylum affiliations and gross morphological traits, plus numbers of replicates featuring each species in each year and level of richness across years. Bryozoans (Phylum Bryozoa) feed by relatively passive ciliary sieving and tentacle flicking, while tunicates (Phylum Chordata) feed by actively pumping water through an internal mucus net

\begin{tabular}{|c|c|c|c|c|c|c|c|c|c|}
\hline \multirow[t]{2}{*}{ Species } & \multirow[t]{2}{*}{ Phylum } & \multirow[t]{2}{*}{ Morphology } & \multirow[t]{2}{*}{ Adult form } & \multirow[t]{2}{*}{2014} & \multirow[t]{2}{*}{2015} & \multicolumn{4}{|c|}{ Species richness } \\
\hline & & & & & & 1 & 2 & 4 & 6 \\
\hline Bugula neritina & Bryozoa & Erect & Colonial & 18 & 60 & 23 & 26 & 8 & 21 \\
\hline Schizoporella unicornis & Bryozoa & Prostrate & Colonial & 0 & 22 & 4 & 6 & 0 & 12 \\
\hline Watersipora subtorquata & Bryozoa & Prostrate & Colonial & 0 & 26 & 8 & 0 & 0 & 18 \\
\hline Ascidia ceratodes & Chordata & Erect & Solitary & 15 & 32 & 18 & 15 & 5 & 9 \\
\hline Botrylloides diegensis & Chordata & Prostrate & Colonial & 0 & 20 & 4 & 4 & 0 & 12 \\
\hline Botrylloides violaceus & Chordata & Prostrate & Colonial & 21 & 52 & 25 & 28 & 5 & 15 \\
\hline Botryllus schlosseri & Chordata & Prostrate & Colonial & 21 & 18 & 8 & 10 & 6 & 15 \\
\hline Ciona intestinalis & Chordata & Erect & Solitary & 36 & 26 & 24 & 26 & 3 & 9 \\
\hline Didemnum vexillum & Chordata & Prostrate & Colonial & 0 & 34 & 14 & 20 & 2 & 0 \\
\hline Diplosoma listerianum & Chordata & Prostrate & Colonial & 39 & 29 & 21 & 23 & 3 & 21 \\
\hline
\end{tabular}




\section{Experimental chambers}

We built flow chambers from $92 \mathrm{~cm}$ lengths of $15.24 \mathrm{~cm}$ diameter PVC pipe, plumbed on each end with a cap drilled to accommodate a $1.27 \mathrm{~cm}$ diameter Alcryn rubber bulkhead fitting (Uniseal ${ }^{\circledR}$ ). One end was glued shut, while the other was sealed with plumber's putty and held to the opposing end cap with rubber straps (ULINE ${ }^{\circledR}$ ). Ball valves on each side of the chamber allowed the regulation of water flow. Vinyl tubing $(1.27 \mathrm{~cm})$ connected each end of the flow chambers to a 37.85 l aquarium tank sump, and a small aquarium pump (AquaClear ${ }^{\circledR} 110 \mathrm{~V}$, $14 \mathrm{~W}$ ) was attached to one of these tubes to generate unidirectional, albeit turbulent, flow through the chamber. A small hole was drilled in the top of chambers to accommodate a stopcock, which allowed us to maintain full chambers throughout experimental trials (see Fig. 1).

We assembled consumer communities on a 12 tile $x$ 12 tile grid collected from the field and attached to a square area $\left(103.2 \mathrm{~cm}^{2}\right)$ on a PVC sheet using hook and loop tape. We included an extension of $50 \mathrm{~cm}$ on one side of this PVC sheet to reduce interaction between flowing water and the edge of the PVC sheet containing tiles with consumers. Each sheet with a community of consumers was installed into flow chambers by sliding it between 2 strips of aluminum shelving uprights glued into the downstream half of the chamber parallel to flow. In this way, communities faced the bottom as they did while growing in the field.

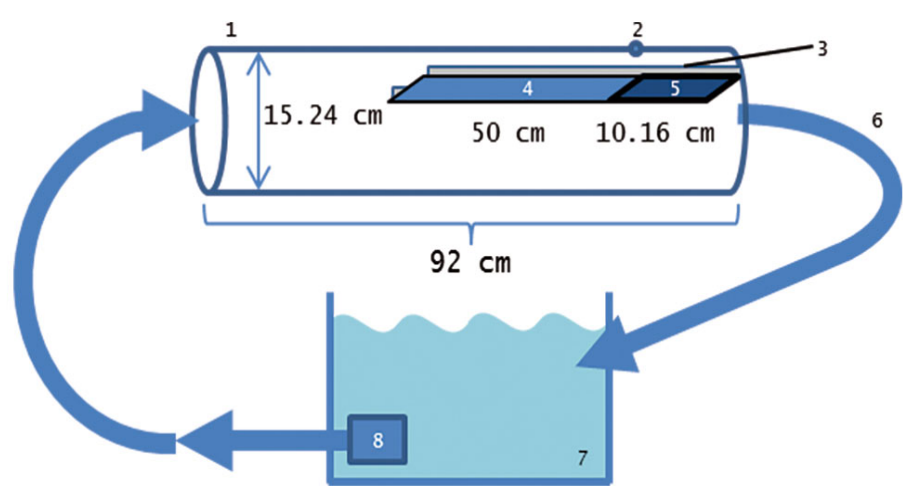

Fig. 1. Schematic of experimental flow chamber system, containing the following components: (1) PVC pipe (the working chamber), (2) air release valve, (3) shelving strips, (4) PVC sheet extension, (5) PVC plate for attachment of tiles with animals, (6) aquarium tubing with flow control ball valves (both ends of chamber), (7) aquarium sump, (8) aquarium pump

\section{Filtration experiments}

We ran a total of 19 experimental trials on different days. For a given experimental trial, we simultaneously ran up to 16 flow and 12 no-flow replicates in the same indoor space at Bodega Marine Laboratory. In nearly all trials with consumer polycultures, we included monocultures of each species to control for withinspecies variation across trials. Before and during trials, we adjusted water flow in flow treatments to achieve directional flow of approximately $5 \mathrm{~cm} \mathrm{~s}^{-1}$, which likely exceeds the maximum flow experienced by suspension feeders at our site (Rasmussen et al. 2004).

In no-flow treatments, we assembled communities onto an identical square plate $\left(103.2 \mathrm{~cm}^{2}\right)$ and suspended it directly into the aquarium tank sump. None of the other equipment for the flow chamber was included, but air was bubbled into the sump away from the animals, and water was mixed gently and thoroughly before each phytoplankton sample to avoid sampling an overly depleted area. The total volume of water in the system and initial concentration of phytoplankton was the same in treatments with and without flow.

We started each experimental trial by filling each aquarium sump with natural seawater filtered to $1 \mu \mathrm{m}$, introducing consumer communities to flow chambers and sumps, and adding cultured phytoplankton to each experimental unit. We tracked changes in phytoplankton concentration several times over the course of each trial by measuring in vivo fluorescence of the seawater in the aquarium sump. We restricted our analyses to the first $8 \mathrm{~h}$ of filtration when fluorescence was measured every 1 to $2 \mathrm{~h}$. Each sample was the average of 3 measurements each using $3 \mathrm{ml}$ of seawater. All experimental units were shaded to prevent growth of phytoplankton. We were not able to achieve the same concentration of phytoplankton across trials due to logistical constraints, but within trials, concentrations provided to each replicate were equal. Initial phytoplankton concentrations did not influence the time course of fluorescence in consumer-free controls, but we detected a modest negative relationship between initial chlorophyll concentration and filtration rates (see Figs. S1 \& S2 in the Supplement). However, this relationship did not influence any subsequent analysis, so we did not include initial fluorescence as a covariate.

\section{Flow cytometry}

To determine whether filtration was size selective, a potential mechanism for complementarity, we used 
flow cytometry (CytoBuoy, Woerden, Netherlands) to estimate size distributions of phytoplankton before and after 6 experimental trials from 2015 in which we tested 7 of our consumer monocultures, 10 species pairs, and one 4 species mixture. Shortly after adding phytoplankton to experimental units, we collected $20 \mathrm{ml}$ of water from each aquarium tank in glass scintillation vials and immediately placed samples on ice and held them in refrigeration. We collected samples in the same way at the end of each trial between 12 and $15 \mathrm{~h}$ after the first samples were collected. Samples were then taken in a cooler to Romberg Tiburon Center where they were analyzed within $24 \mathrm{~h}$. Samples were gently but thoroughly mixed by hand before analysis. We used the average forward scatter of each particle as a proxy for cell size. This metric is less sensitive than side scatter to the orientation of particles, which can be important for non-spheroid phytoplankton, and is proportional to cell diameter. The detection threshold for particles was $1 \mu \mathrm{m}$ in diameter with a minimum red fluorescence (734 to $668 \mathrm{~nm}$ ) of 30 arbitrary units. Each sample was run for at least $10 \mathrm{~s}$.

\section{Statistical analysis}

Our measure of ecosystem functioning was community filtration: the change in phytoplankton in vivo fluorescence (as a proxy for biomass) over time in a consumer treatment relative to consumer-free controls in each trial. In the first stage of our analysis, we estimated exponential decay rates of fluorescence separately for each flow treatment in each trial (different days on which experiments were run) using linear mixed effects models that allowed the change in natural log-transformed fluorescence over time to vary randomly for each replicate community. These models included fixed effects of time, consumer presence $(0=$ consumer-free control, $1=$ consumers present), and their interaction. For each consumer $\times$ flow combination, we estimated the decay rate due to consumption alone by subtracting the decay rate of fluorescence in the consumer treatment from that in the consumer-free control. Then, to incorporate variation around the mean response, we added a random slope for each replicate to generate point estimates of community filtration rate. We then used each rate as a datum that we analyzed with linear mixed effects models testing effects of treatments and species traits, while accounting for variation among experimental trials. All analyses used our filtration rate estimates, but we display graphical results as percent change in phytoplankton over an $8 \mathrm{~h}$ period, the period of time over which phytoplankton assemblages might be in residence within an invertebrate habitat (e.g. a marina) due to tidal oscillations.

We tested for the influences of species richness and flow treatment on community filtration rates using the entire dataset. We fit 2 linear mixed effects models that included both random intercepts for consumer treatment and experimental trial and fixed effects of species richness and flow treatment. One model included an interaction between species richness and flow treatment, while the other did not. We compared these 2 models using a Chi-squared test with 1 degree of freedom to determine whether the relationship between diversity and filtration depended on water flow. In order to assess how the relationship between consumer species richness and community filtration depended on community composition, we independently fit linear mixed effects models to data from each of our highest diversity (6 species) communities and all possible nested subsets of those communities in each flow condition.

We compared the performance of monocultures and pairs in different flow conditions to assess the net effect of particular species interactions on community filtration. First, we compared filtration rates of pairs to our expectations from monoculture by testing whether the proportional difference between observed and expected filtration was different from zero. Because each pair assemblage contained half the number of individuals of each species relative to the corresponding monocultures in our replacement design, our expectation was simply the average of each species' filtration rate, which assumes that filtration is a linear function of abundance. We included all monoculture data, regardless of whether a particular pair was included in the same experimental trial as its constituent monocultures. Next, we compared models of filtration rates of all monocultures and pairs as functions of species richness (1 vs. 2 species) and traits (feeding mode, morphology, and relative growth rate). For these sets of comparisons of filtration by monocultures and pairs, we used AICc to rank models. Finally, we assessed the response of each species to flow in monoculture using models with different combinations of fixed effects for species, flow treatment, and their interaction, and random intercepts for experimental trial.

Flow cytometry data were analyzed graphically by overlaying natural log-transformed kernel density estimates of particle size distributions of samples before and after trials for each replicate (see Fig. S3 in the Supplement). We then compared these 2 distri- 
butions using quantile-quantile plots. Finally, we calculated Kullback-Leibler (KL) divergence between the 2 distributions using initial samples before trials as the expectation. KL divergence describes how much information in one distribution is captured by another (Burnham \& Anderson 2002). We used a linear mixed effects model to predict these divergence estimates as a function of consumer treatment, flow treatment, and their interaction, with random intercepts for each experimental trial.

All analyses were run in R 3.3.1 (R Development Core Team 2016). Mixed effects models were fitted using the function 'Imer' in R package 'Ime4' (Bates et al. 2015). We calculated p-values describing effects of predictors for these models using the Satterthwaite approximation of denominator degrees of freedom in package 'ImerTest' (Kuznetsova et al. 2015).

\section{RESULTS}

\section{Filtration as a function of flow and total diversity}

We found that consumer species richness increased community filtration rates, and flow decreased these rates. Over an $8 \mathrm{~h}$ period, assemblages with 6 species reduced in vivo fluorescence (our proxy for phytoplankton biomass) by $48 \%$, on average, compared to $31 \%$ for the average single species assemblage (Fig. 2, Table 2). The shape of the richness-filtration relationship was essentially identical in flow and noflow treatments (Chi-squared test for model with and without richness $\times$ flow interaction: $\chi^{2}=0.27, \mathrm{df}=1$, $\mathrm{p}=0.61$ ), so we did not include an interaction term in our final analysis. The intercept was more negative in the no-flow treatment than in flow, indicating that flow reduced overall consumption in our experimental systems, even though the effect of richness did not differ between flow treatments. Across consumer treatments, communities cleared $41 \%$ of the phytoplankton in the no-flow treatment and $33 \%$ in the flow treatment. Therefore, effects of consumer richness and water flow were comparable in determining community filtration across the ranges we investigated.

Although the mean effect of richness on filtration was the same in both flow conditions, both the magnitude and direction of the diversity effect varied with species composition in the flow treatments and were strikingly consistent regardless of composition

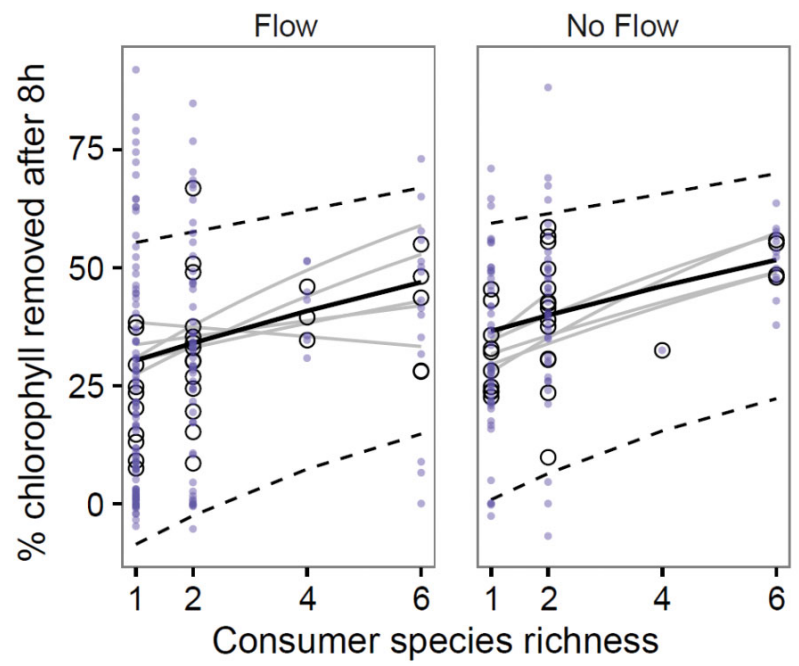

Fig. 2. Community filtration as a function of consumer species richness and water flow treatment. Filtration is shown as the predicted percentage of phytoplankton biomassmeasured as chlorophyll a-removed after an $8 \mathrm{~h}$ period, but models were run using instantaneous rates. Transparent blue dots represent estimates for individual replicates, while larger open black circles represent mean predictions for each consumer treatment. The solid black lines show predictions from a linear mixed model, and dashed black lines are $95 \%$ confidence intervals (including variance in random effects) around the slopes. The gray lines show individual linear mixed effects models for each set of consumer treatments nested in each 6 species treatment

in no-flow conditions (gray lines in Fig. 2). Species pairs consistently filtered faster on average than our expectation from average filtration rates of monocultures ( $p=0.002$; Fig. 3). This deviation from expectation was similar for assemblages with different morphological composition (i.e. prostrate, flat, or mixed) and between flow conditions. In only 1 pair (Bugula + Diplosoma; mixed morphology) did we find that average filtration of the pair was lower than expected in both flow conditions, but we lacked sufficient replication to test for species level differences in observed and expected filtration of pairs.

Table 2. Results of a linear mixed effects model predicting community filtration rate as a function of consumer richness and flow treatment. Consumer treatment and experimental trial were included as random intercepts. We did not include an interaction between richness and flow in this analysis (Chi-squared test for model with and without richness $\times$ flow interaction, $\chi^{2}=0.27$, $\mathrm{df}=1$, $\mathrm{p}=0.61$ ). Model predictions are presented in Fig. 2

\begin{tabular}{|lrrrrr|}
\hline Model term & $\begin{array}{c}\text { Parameter } \\
\text { estimate }\end{array}$ & $\begin{array}{c}\text { Standard } \\
\text { error }\end{array}$ & df & $t$ & $p$ \\
\hline Intercept & -0.0384 & 0.0081 & 31.8 & -4.72 & $<0.001$ \\
Consumer richness & -0.0068 & 0.0029 & 45.8 & -2.36 & 0.023 \\
Flow treatment & 0.0116 & 0.0053 & 219.6 & -2.21 & 0.028 \\
\hline
\end{tabular}




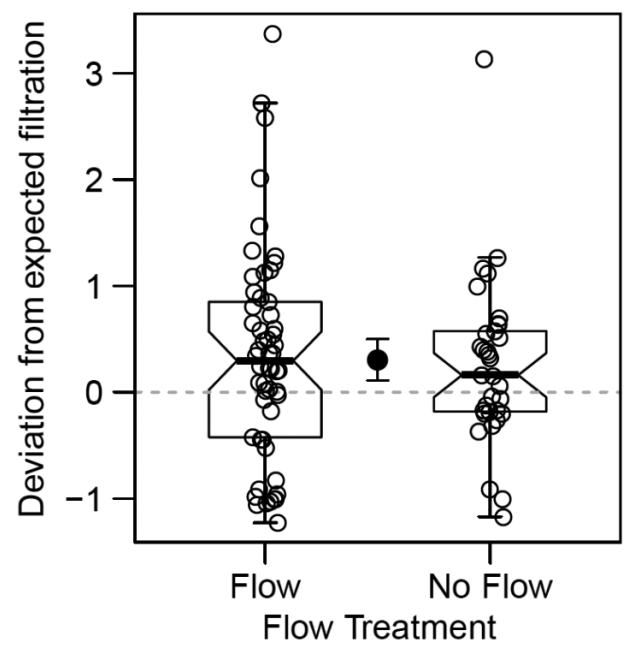

Fig. 3. Deviation of observed filtration by species pairs from expectations based on mean monoculture performance in flow and no-flow treatments. Boxes extend to 0.25 and 0.75 quartiles of the data, the median is shown by a bar in the box, and the box notches show 95\% confidence intervals around the median. Whiskers extend to 1.5 -fold the interquartile range or the range of the data points, whichever is less extreme. Individual data points are offset to improve visualization. The dashed horizontal line denotes no difference between expected and observed filtrations of pairs. The point and error bar in the center of the plot show the parameter estimate and $95 \%$ confidence intervals for the intercept in a model of the average deviation of species pair filtration across flow treatments

\section{Using species pairs to assess effects of consumer traits on filtration rate}

The best predictor of filtration by monocultures and pairs was water flow treatment, which was retained in the 4 top models with a cumulative Akaike weight of 0.71 (sum of AIC weights for top 4 models: Table 3). Flow tended to reduce filtration $(\mathrm{p}=0.042)$. Beyond flow, consumer richness, consumer morphology, and consumer taxonomy were also reasonable predictors that appeared in these top-ranked models. However, our ability to discriminate between models with these terms was weak. The highest-ranked model included flow treatment and was only 2.7fold more likely than the interceptonly model, and the model with species richness (1 vs. 2 species) and flow treatment was nearly indistinguishable from the model with only flow treatment $(\triangle \mathrm{AICc}=$ 0.1 ; Table 3 ). The model with flow treatment and consumer morphology explained the highest proportion of variance (conditional $R^{2}=0.38$; Nakagawa \& Schielzeth 2013). Assemblages with a mixture of prostrate and erect species tended to filter $26 \%$ faster than communities with only prostrate or erect species, but these differences were not statistically significant $(p=0.18)$. We did not include models with multiple terms related to consumer assemblages (i.e. identity, richness, or traits) because these model terms were often highly correlated. However, water flow and, to a lesser degree, consumer traits helped explain filtration rate patterns of monocultures and pairs.

\section{Filtration by monoculture assemblages}

All monoculture assemblages reduced phytoplankton biomass relative to the no-consumer controls. The best model predicting filtration rate in monoculture contained only the intercept (Akaike weight $=0.73$, Intercept $=-0.053, p<0.001$ ), suggesting that variation among species is less than what is detectable with our power. However, we also describe models accounting for consumer species identity and flow because we were interested in the magnitude and direction of water flow effects on filtration by single species. Watersipora subtorquata, a prostrate colonial bryozoan, had the lowest filtration rates across flow conditions (Table 4). Solitary tunicates (native Ascidia and non-native Ciona) were among the fastest filterers, as expected, in both flow and no-flow treatments. Across flow conditions, Ciona cleared $43 \%$ of the phytoplankton biomass after $8 \mathrm{~h}$ and was the fastest

Table 3. Comparison of models predicting community filtration for monocultures and pairs using Akaike information criterion corrected for small sample size (AICC). The evidence ratio describes how much more likely the model with the lowest AIC is relative to each model

\begin{tabular}{|lccrccc|}
\hline $\begin{array}{l}\text { Fixed effect model } \\
\text { terms }\end{array}$ & AICc & AAICc & df & $\begin{array}{c}\text { Akaike } \\
\text { weight }\end{array}$ & $\begin{array}{c}\text { Cumula- } \\
\text { tive weight }\end{array}$ & $\begin{array}{c}\text { Evidence } \\
\text { ratio }\end{array}$ \\
\hline Flow & -785.4 & 0 & 5 & 0.249 & 0.25 & 1 \\
Flow + Richness & -785.3 & 0.1 & 6 & 0.237 & 0.49 & 1.1 \\
Flow + Morphology & -784.0 & 1.4 & 7 & 0.125 & 0.61 & 2 \\
Flow + Taxonomy & -783.6 & 1.8 & 7 & 0.101 & 0.71 & 2.5 \\
Richness & -783.6 & 1.8 & 5 & 0.099 & 0.81 & 2.5 \\
Intercept-only & -783.4 & 2.0 & 4 & 0.093 & 0.90 & 2.7 \\
Morphology & -782.2 & 3.2 & 6 & 0.050 & $>0.99$ & 5 \\
Taxonomy & -781.5 & 3.9 & 6 & 0.036 & $>0.99$ & 7 \\
Flow + Growth & -778.2 & 7.3 & 10 & 0.007 & $>0.99$ & 37.7 \\
Growth & -775.9 & 9.5 & 9 & 0.002 & $>0.99$ & 117.3 \\
Flow + Composition & -766.9 & 18.5 & 29 & $<0.001$ & $>0.99$ & 10311.2 \\
Composition & -764.4 & 21.0 & 28 & $<0.001$ & $>0.99$ & 36198.8 \\
\hline
\end{tabular}


Table 4. Filtration by monoculture species across flow conditions predicted by linear mixed effects model with random effects of flow treatment and experimental trial. Both instantaneous clearance rates and predictions over an $8 \mathrm{~h}$ period are provided. The model and the statistical test used the instantaneous rates

\begin{tabular}{|lcccrr|}
\hline Species & $\begin{array}{c}\text { Instantaneous } \\
\text { clearance rate } \\
\left(\mathrm{h}^{-1}\right)\end{array}$ & $\begin{array}{c}8 \mathrm{~h} \\
\text { clearance } \\
(\%)\end{array}$ & $\mathrm{df}$ & $t$ & $\mathrm{p}$ \\
\hline Ciona intestinalis & -0.0695 & 42.67 & 36.05 & -6.424 & $<0.001$ \\
Botrylloides diegensis & -0.0674 & 41.68 & 76.59 & -2.898 & 0.005 \\
Ascidia ceratodes & -0.0648 & 40.46 & 45.06 & -5.424 & $<0.001$ \\
Botryllus Schlosseri & -0.0608 & 38.54 & 96.72 & -3.734 & $<0.001$ \\
Botrylloides violaceus & -0.0575 & 36.86 & 31.66 & -5.400 & $<0.001$ \\
Diplosoma listerianum & -0.0557 & 35.95 & 46.36 & -4.789 & $<0.001$ \\
Schizoporella unicornis & -0.0481 & 31.94 & 91.96 & -2.158 & 0.034 \\
Bugula neritina & -0.0464 & 31.03 & 37.33 & -4.033 & $<0.001$ \\
Didemnum vexillum & -0.0411 & 28.00 & 41.26 & -2.975 & 0.005 \\
Watersipora subtorquata & -0.0386 & 26.56 & 43.33 & -2.018 & 0.050 \\
\hline
\end{tabular}

Table 5. Analysis of variance for results of linear mixed effects model predicting Kullback-Leibler divergence between pre-trial and post-trial phytoplankton size distributions as a function of flow treatment, consumer treatment, and their interaction. Phytoplankton sizes were estimated using flow cytometry

\begin{tabular}{|lcccccc|}
\hline Model term & SS & MS & Num df & Den df & $F$ & $p$ \\
\hline Flow Treatment & 0.008 & 0.008 & 1 & 68.30 & 0.064 & 0.802 \\
Consumer Treatment & 1.866 & 0.104 & 18 & 69.21 & 0.853 & 0.634 \\
Flow $\times$ Consumer & 1.509 & 0.084 & 18 & 68.30 & 0.690 & 0.809 \\
\hline
\end{tabular}

Fig. 4. Mean predicted change in filtration by monoculture communities under flow relative to no-flow conditions shown as percentage difference of filtration in flow relative to no flow. Most species filtered as well in the presence of flow as in its absence. For full species names, see Table 1, and for predictions in each flow treatment, see Fig. S4 in the Supplement

filtering species. Colonial tunicates showed the greatest range in filtration, including several species that filtered nearly as fast as solitary tunicates, although we sampled more species from this functional group because there were more present in local assemblages. As found previously in this community (Byrnes \& Sta- chowicz 2009), native Botrylloides diegensis filtered faster ( $42 \%$ cleared after $8 \mathrm{~h}$ ) than its non-native congener, Botrylloides violaceus (37\%). Difference in filtration between monocultures in flow $(28 \%$ cleared after $8 \mathrm{~h}$, on average) and no-flow ( $34 \%$ ) were smaller $(p=0.083)$ than when considering all levels of consumer richness, and we found no interaction between consumer treatment and flow treatment $(p=0.773)$. Despite the lack of statistically significant differences in monoculture filtration between flow treatments, 4 of 10 monoculture communities experienced mean reductions or increases in filtration of $>25 \%$ (Fig. 4, Fig. S4 in the Supplement) that may represent biologically meaningful responses to flow.

\section{Using flow cytometry to infer size selective feeding}

We found little evidence that the size frequency distributions of suspended particles differed before vs. after experimental trials (Table 5, Fig. 4, Fig. S4). Our models of Kullback-Leibler divergence estimates showed no effect of either consumer treatment (i.e. they did not differ from control treatments), flow treatment, or their interaction. This suggests that across the range of cell sizes provided in our experiments, consumers were not size selective in their feeding. Based on visual inspection of quantilequantile plots, there is some evidence for slightly higher representation of the largest particle sizes after consumer treatments were applied (i.e. above the 1:1 line in Fig. 4), but most of these represent particles larger than what we provided initially and thus may reflect accumulation of feces rather than greater relative consumption of smaller cells.

\section{DISCUSSION}

Rates of community-level water filtration increased with suspension feeder species richness in both the presence and absence of flow. The magnitude of this relationship was identical in both flow conditions, despite substantial variation in individual species responses to flow and performance of consumer poly- 
cultures relative to monocultures. The fastest filtering species in monoculture (Ciona intestinalis) filtered slightly slower than the average 6 species polyculture $(43 \%$ vs. $48 \%$ phytoplankton biomass cleared after $8 \mathrm{~h}$ across flow treatments), yet inclusion of this species in pairs tended to increase filtration above expectations based on monoculture rates. Communities composed of pairs generally filtered faster than our expectations for constituent monocultures, suggesting that species interactions-including potential reductions of intraspecific competition-were responsible for diversity effects in different flow conditions, although the mechanisms underlying these effects may be diverse and remain elusive. Below, we discuss potential mechanisms underlying the patterns we observed and their implications for biodiversity-ecosystem functioning theory.

Higher average filtration in the no-flow treatment is likely a result of turbulent interference to feeding in flow, which we would expect for consumers with small, relatively passive feeding structures like bryozoans (Okamura 1984, 1985). However, the wide variation we observed in individual species responses to flow suggests that while general feeding mechanisms are well conserved in closely related taxa, the performance of those mechanisms in different species are not equally sensitive to environmental conditions. For example, 2 invasive colonial tunicates in the same family, Diplosoma listerianum and Didemnum vexillum, both with similar sized zooids and pharyngeal basket morphology but different tunic rigidity (Carlton 2007), showed opposite responses to flow (Fig. 4), adding evidence to strong niche differentiation in this species pair (Edwards \& Stachowicz 2010). While flow increases turbulence, it also leads to greater resource flux, and if consumers are able to quickly exhaust resources around them, flow may ameliorate resource limitation. This may be a possible explanation for monoculture communities that filtered faster in flow than no flow (e.g. Diplosoma, Botryllus, both of which are fast-growing relative to other species we used; Edwards \& Stachowicz 2010).

In polycultures, we cannot attribute specific filtration rates to individual organisms, precluding a clear partitioning of sampling vs. complementarity effects like that commonly done for biomass (Loreau \& Hector 2001, Fox 2005). However, our replacement experimental design should reduce impacts of species identity in high-diversity treatments because the density of individual species decreases with increasing richness. We expect that in general, filtra- tion rates should scale with the density of each species, although it is important to note that monocultures may experience intraspecific competition that could limit community filtration at high density. Even though the abundance of the strongest filtering species was $1 / 6^{\text {th }}$ of what it was in monoculture, our highest diversity treatments filtered slightly faster than the best performing monoculture. This overyielding is common when species identity and weak resource complementarity among species contributes to functioning (Stachowicz et al. 2007). This may be especially true in experiments of short duration (Stachowicz et al. 2008), but given the amount of prey turnover with the tides in our system, this pattern of richness effects may be realistic. Over longer stretches of time, however, consumer diversity can buffer community filtration as consumer species with different phenologies turn over seasonally (Byrnes \& Stachowicz 2009)

Interestingly, the degree to which the general relationship between species richness and water filtration held for nested subsets of polycultures differed between flow treatments (Fig. 2). In the absence of flow, high-diversity communities that differed in composition all filtered at similar rates, while in flow, variation around the average response was much greater. These patterns were not clearly related to the presence of particular consumer species or morphological forms. For instance, two of our 6-species communities lacked solitary tunicates (Ascidia and Ciona), the species whose filtration rates in monoculture were highest. For one of these communities and its constituent monocultures, the relationship with species richness was weaker in flow (Richness $\times$ Flow; $p=0.017$ ), yet this relationship was nearly identical for the other community across flow conditions $(p=0.599)$. However, the patterns suggest that both individual responses to flow and changes in species interactions with flow propagated to higher diversity treatments. Thus, flow could enhance complementarity through facilitation or it could depress diversity effects through shared responses to environmental stress.

Our finding that relative filtration rates of pairs and monocultures depended on consumer morphology and flow treatment suggests that flow treatments altered species interactions in ways that affected community rates of feeding. Communities that include organisms with different morphologies (i.e. erect and prostrate forms) result in each species feeding at different heights in the water column, which could lead to resource complementarity akin to different rooting depths of terrestrial plants. However, 
these height differences take on new importance in water flow as organisms can modify the local flow environments experienced by downstream neighbors (Cardinale \& Palmer 2002).

When water flows past an organism that is taller than the height of the boundary layer, eddies can form, creating localized areas of recirculation and low flow. Organisms downstream of erect species will likely experience very different physical environments than they would if no obstacles were upstream. For species that experience feeding interference from water flow, obstacles to flow will likely facilitate feeding. For example, both Ascidia and Botrylloides violaceus monocultures experienced filtration reductions in flow (Fig. 4), but assemblages of these 2 species outperformed expectations in flow ( $p=0.014$ ) but not in the absence of flow. However, we observed a great deal of variation in how pairs with mixed morphologies responded to flow, suggesting that local flow reductions can also reduce feeding in some communities (e.g. Cardinale \& Palmer 2002). Additionally, suspension feeding invertebrates with active feeding mechanisms generate flow when feeding and respiring, so organisms with stronger pumping activity like solitary tunicates may be able to modify local flow environments of their neighbors, even when ambient water flow is low. Therefore, environmental heterogeneity generated by organisms, and its interaction with other forms of spatial and temporal heterogeneity, can impact ecosystem functioning.

Our experiments were of a suitable duration to measure consumption of a pulsed supply of food that might be delivered during a tidal cycle. They do not consider how the interactions between flow and organisms will influence ecosystem functioning over longer time scales (e.g. seasons, varying sea states, or sections of the lunar tidal cycle). If diverse communities are able to quickly draw down resources when flow is absent or sufficiently slow, food limitation could result and alter community trajectories (Svensson \& Marshall 2015). Flow might also act to accelerate overgrowth of species when neighbors facilitate one another's feeding. This is likely to lead to higher rates of competitive exclusion when space is limiting (Jackson \& Buss 1975, Buss 1979). Even during the short duration of our experiments, some horizontal growth of prostrate species onto neighboring tiles occurred (pers. obs.), although this did not likely affect filtration.

Based on feeding structure morphology, we hypothesized that species might be complementary in their use of different size classes of phytoplankton, which could generate additional complementarity in resource use. However, our flow cytometry data suggests this was not the case as no species or mixtures of species seemed to alter the size distributions of particles (Table 5, Fig. 5). Importantly, this lack of size-selectivity suggests that the composition of the food sources we used would not have influenced filtration, unless prey species are differentially rejected based on other traits (e.g. defensive chemicals). However, we would expect that a broader range of suspension feeder species (e.g. sponges, mussels) and planktonic food resources (e.g. microbes, zooplankton) could generate additional layers of resource complementarity as more interactions between and across trophic levels are considered (Duffy et al. 2007).

It would be difficult to scale up the results of our laboratory experiments to field conditions where processes acting to shape communities over space and time are at play and where oceanographic processes influence the composition and delivery of food. For instance, behavioral shifts (e.g. Young \& Braithwaite 1980, Okamura 1987, Trager et al. 1990), plastic morphological changes (e.g. Helmuth \& Sebens 1993, Okamura \& Partridge 1999, Li \& Denny 2004), and compositional turnover due to physiological, mechanical, and resource limitation (e.g. LaBarbera 1984, Leichter \& Witman 1997) likely influence community filtration in areas that differ in water flow regimes. However, morphological and feeding traits that contribute to functions other than size selectivity appear to drive diversity effects in our study. These traits may instead cause flow modification or susceptibility to flow that relates to feeding biology. Other important mechanisms that could influence community filtration include temporal complementarity in consumer abundance (Byrnes \& Stachowicz 2009) and complementarity in microhabitat use, both of which could be influenced by flow (Koehl et al. 2013). The degree to which these putative mechanisms for diversity effects on ecosystem functioning interact remains an open and interesting avenue of research.

Acknowledgements. This work was funded by an Environmental Protection Agency STAR Fellowship to M.A.W. and additionally supported by the UC Davis Graduate Group in Ecology and Center for Population Biology. We sincerely thank R. Dugdale and F. Wilkerson at Romberg Tiburon Center (San Francisco State University) and their lab for access to the flow cytometer. These experiments would not have been possible without the assistance of J. Toy and K. Norris. We also thank L. Heidenreich, L. Leveque-Eichorn, A. Kruger, and S. King for laboratory assistance, and B. Gaylord for helpful discussions. 

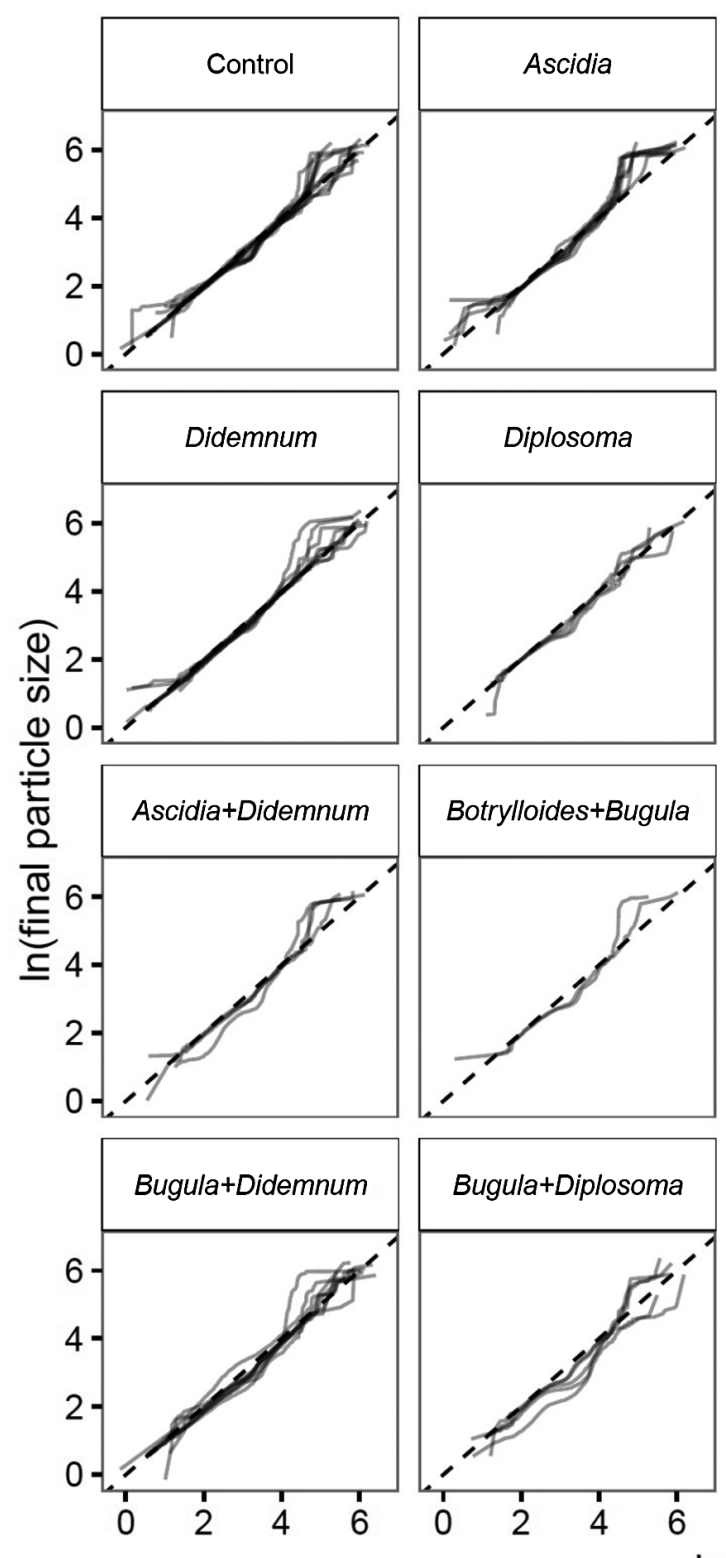
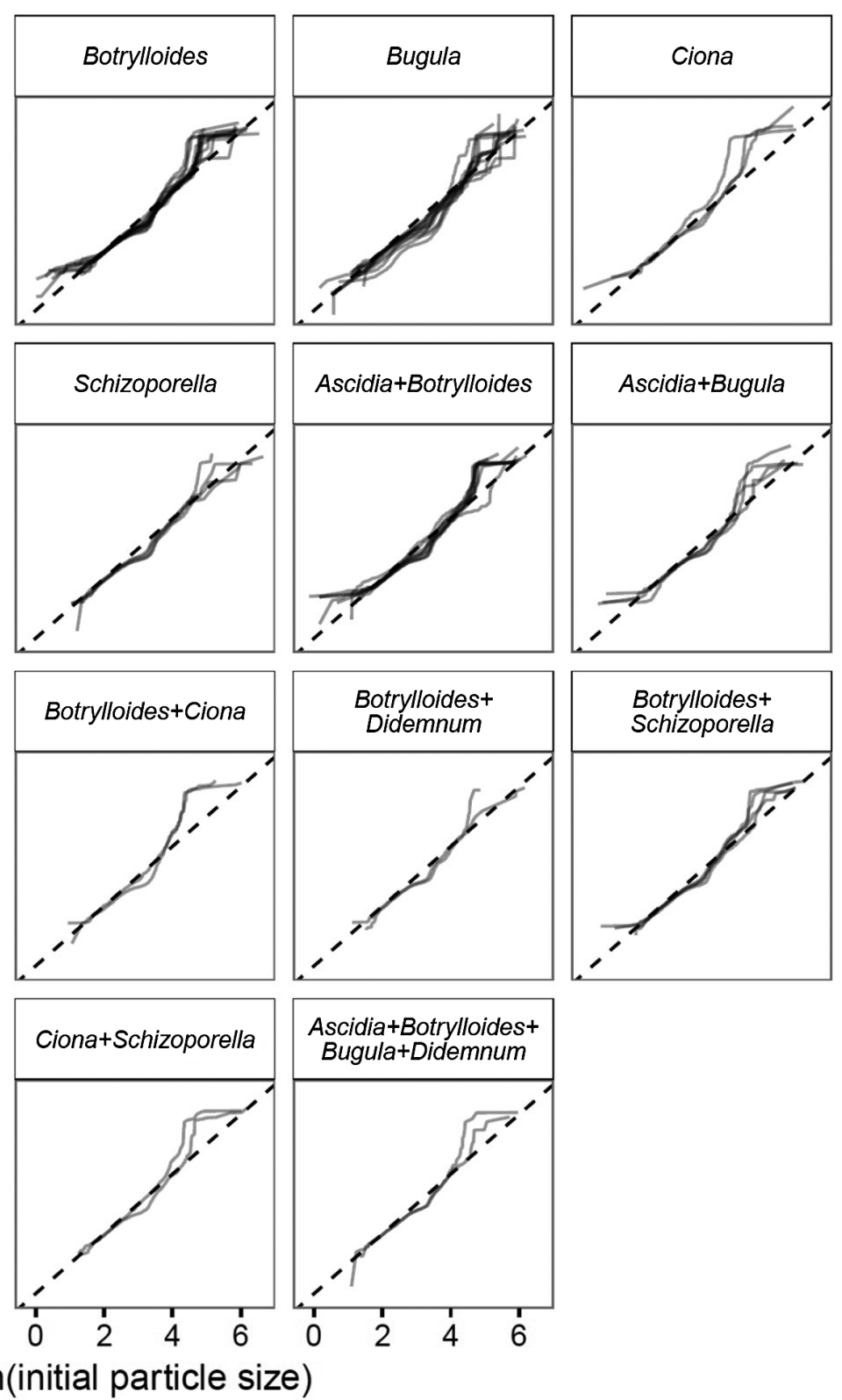

Fig. 5. Quantile-quantile plots of size frequency distributions before ( $x$-axis) and after ( $y$-axis) experimental trials. Frequency distributions estimated by kernel density on natural log-transformed data. Distribution comparisons arranged by consumer treatment. Deviations above the dashed 1:1 line indicate more particles of a particular size after the experiment. For full species names, see Table 1 (here, Botrylloides is B. violaceus)

\section{LITERATURE CITED}

Bates D, Maechler M, Bolker B, Walker S (2015) Fitting linear mixed-effects models using lme4. J Stat Softw 67: $1-48$

Boyer KE, Kertesz JS, Bruno JF (2009) Biodiversity effects on productivity and stability of marine macroalgal communities: the role of environmental context. Oikos 118: 1062-1072

Bruno JF, Stachowicz JJ, Bertness MD (2003) Inclusion of facilitation into ecological theory. Trends Ecol Evol 18: $119-125$
Burnham KP, Anderson DR (2002) Multimodel selection and multimodel inference: a practical information-theoretic approach. Springer-Verlag, New York, NY

Buss LW (1979) Bryozoan overgrowth interactions-the interdependence of competition for space and food. Nature 281:475-477

* Byrnes J, Stachowicz JJ (2009) Short and long term consequences of increases in exotic species richness on water filtration by marine invertebrates. Ecol Lett 12:830-841

Cardinale BJ (2011) Biodiversity improves water quality through niche partitioning. Nature 472:86-89

Cardinale BJ, Palmer MA (2002) Disturbance moderates 
biodiversity-ecosystem function relationships: experimental evidence from caddisflies in stream mesocosms. Ecology 83:1915-1927

* Cardinale BJ, Matulich KL, Hooper DU, Byrnes JE and others (2011) The functional role of producer diversity in ecosystems. Am J Bot 98:572-592

Carlton JT (ed) (2007) The Light and Smith manual: intertidal invertebrates from Central California to Oregon, 4th edn. University of California Press, Berkeley, CA

*Duffy JE, Cardinale BJ, France KE, McIntyre PB, Thébault E, Loreau M (2007) The functional role of biodiversity in ecosystems: incorporating trophic complexity. Ecol Lett 10:522-538

Edwards KF, Stachowicz JJ (2010) Multivariate trade-offs, succession, and phenological differentiation in a guild of colonial invertebrates. Ecology 91:3146-3152

Eklöf JS, Alsterberg C, Havenhand JN, Sundbäck K, Wood HL, Gamfeldt L (2012) Experimental climate change weakens the insurance effect of biodiversity. Ecol Lett 15:864-872

Fox JW (2005) Interpreting the 'selection effect' of biodiversity on ecosystem function. Ecol Lett 8:846-856

* Gamfeldt L, Lefcheck JS, Byrnes JEK, Cardinale BJ, Duffy JE, Griffin JN (2015) Marine biodiversity and ecosystem functioning: What's known and what's next? Oikos 124: 252-265

* He Q, Bertness MD, Altieri AH (2013) Global shifts towards positive species interactions with increasing environmental stress. Ecol Lett 16:695-706

*Helmuth B, Sebens K (1993) The influence of colony morphology and orientation to flow on particle capture by the scleractinian coral Agaricia agaricites (Linnaeus). J Exp Mar Biol Ecol 165:251-278

Holmes N (1973) Water transport in the ascidians Styela clava Herdman and Ascidiella aspersa (Müller). J Exp Mar Biol Ecol 11:1-13

* Jackson JBC, Buss L (1975) Allelopathy and spatial competition among coral invertebrates. Proc Natl Acad Sci USA 72:5160-5163

Koehl MAR, Crimaldi JP, Dombroski DE (2013) Wind chop and ship wakes determine hydrodynamic stresses on larvae settling on different microhabitats in fouling communities. Mar Ecol Prog Ser 479:47-62

Kuznetsova A, Brockhoff PB, Christensen RHB (2015) lmerTest: tests in linear mixed effects models. R Package Version 2.0-29. https://CRAN.R-project.org/package= lmerTest

LaBarbera M (1984) Feeding currents and particle capture mechanisms in suspension feeding animals. Am Zool 24: 71-84

Leichter JJ, Witman JD (1997) Water flow over subtidal rock walls: relation to distributions and growth rates of sessile suspension feeders in the Gulf of Maine. J Exp Mar Biol Ecol 209:293-307

* Li NK, Denny MW (2004) Limits to phenotypic plasticity: flow effects on barnacle feeding appendages. Biol Bull 206:121-124

Loreau M, Hector A (2001) Partitioning selection and complementarity in biodiversity experiments. Nature 412:72-76

Nakagawa S, Schielzeth H (2013) A general and simple method for obtaining $\mathrm{R}^{2}$ from Generalized Linear Mixedeffects Models. Methods Ecol Evol 4:133-142

Norberg J, Swaney DP, Dushoff J, Lin J, Casagrandi R, Levin SA (2001) Phenotypic diversity and ecosystem functioning in changing environments: a theoretical framework.
Proc Natl Acad Sci USA 98:11376-11381

* O'Connor NE, Bracken MES, Crowe TP, Donohue I (2015) Nutrient enrichment alters the consequences of species loss. J Anim Ecol 103:862-870

* Okamura B (1984) The effects of ambient flow velocity, colony size, and upstream colonies on the feeding success of bryozoa. I. Bugula stolonifera Ryland, an arborescent species. J Exp Mar Biol Ecol 83:179-193

* Okamura B (1985) The effects of ambient flow velocity, colony size, and upstream colonies on the feeding success of Bryozoa. II. Conopeum reticulum (Linnaeus), an encrusting species. J Exp Mar Biol Ecol 89:69-80

\%okamura B (1987) Particle size and flow velocity induce an inferred switch in bryozoan suspension-feeding behavior. Biol Bull 173:222-229

Okamura B, Partridge JC (1999) Suspension feeding adaptations to extreme flow environments in a marine bryozoans. Biol Bull 196:205-215

*Palardy JE, Witman JD (2014) Flow, recruitment limitation, and the maintenance of diversity in marine benthic communities. Ecology 95:286-297

* Patterson MR, Sebens KP (1989) Forced convection modulates gas exchange in cnidarians. Proc Natl Acad Sci USA 86:8833-8836

* Petraitis PS, Latham RE (1999) The importance of scale in testing the origins of alternative community states. Ecology 80:429-442

R Development Core Team (2016) R: a language and environment for statistical computing. R Foundation for Statistical Computing, Vienna, www.R-project.org

Rasmussen L, Largier JL, Carter M (2004) Bodega Harbor circulation study final report. Scripps Institute of Oceanography, La Jolla, CA

* Reich PB, Tilman D, Isbell F, Mueller K, Hobbie SE, Flynn DFB, Eisenhauer N (2012) Impacts of biodiversity loss escalate through time as redundancy fades. Science 336: 589-592

* Riisgård HK, Larsen PS (2010) Particle capture mechanisms in suspension-feeding invertebrates. Mar Ecol Prog Ser 418:255-293

Sebens KP, Johnson AS (1991) Effects of water movement on prey capture and distribution of reef corals. Hydrobiologia 226:91-101

* Stachowicz JJ, Byrnes JE (2006) Species diversity, invasion success, and ecosystem functioning: disentangling the influence of resource competition, facilitation, and extrinsic factors. Mar Ecol Prog Ser 311:251-262

Stachowicz JJ, Whitlatch RB, Osman RW (1999) Species diversity and invasion resistance in a marine ecosystem. Science 286:1577-1579

Stachowicz JJ, Bruno JF, Duffy JE (2007) Understanding the effects of marine biodiversity on communities and ecosystems. Annu Rev Ecol Evol Syst 38:739-766

* Stachowicz JJ, Graham M, Bracken MES, Szoboszlai AI (2008) Diversity enhances cover and stability of seaweed assemblages: the role of heterogeneity and time. Ecology 89:3008-3019

* Suding KN, Lavorel S, Chapin FS III, Cornelissens JHC and others (2008) Scaling environmental change through the community-level: a trait-based response-and-effect framework for plants. Glob Change Biol 14:1125-1140

* Sumerel AN, Finelli CM (2014) Particle size, flow speed, and body size interactions determine feeding rates of a solitary ascidian Styela plicata: a flume experiment. Mar Ecol Prog Ser 495:193-204 
Svensson JR, Marshall DJ (2015) Limiting resources in sessile systems: food enhances diversity and growth of suspension feeders despite available space. Ecology 96: 819-827

Trager GC, Hwang JS, Strickler JR (1990) Barnacle suspension-feeding in variable flow. Mar Biol 105:117-127

*Whalen MA, Aquilino KM, Stachowicz JJ (2016) Grazer diversity interacts with biogenic habitat heterogeneity to accelerate intertidal algal succession. Ecology 97: 2136-2146

Editorial responsibility: Martin Solan, Southampton, UK
Williams SL, Carpenter RC (1998) Effects of unidirectional and oscillatory water flow on nitrogen fixation (acetylene reduction) in coral reef algal turfs, Kaneohe Bay, Hawaii. J Exp Mar Biol Ecol 226:293-316

Yachi S, Loreau M (1999) Biodiversity and ecosystem productivity in a fluctuating environment: the insurance hypothesis. Proc Natl Acad Sci USA 96:1463-1468

\%oung CM, Braithwaite LF (1980) Orientation and currentinduced flow in the stalked ascidian Styela montereyensis. Biol Bull 159:428-440

Submitted: November 21, 2016; Accepted: March 28, 2017

Proofs received from author(s): April 15, 2017 